\title{
Research on environmental impact assessment system and legalization in China
}

\author{
Chen Mingtsung ${ }^{1 *}$ Feng Zhi'an ${ }^{2}$ Qian Wei ${ }^{2}$ Zhang Yujing ${ }^{2}$ \\ ${ }^{1}$ Guangzhou College of Commerce, Guangzhou Guangdong, 511363, China \\ ${ }^{2}$ Nanfang College Guangzhou, Guangzhou, Guangdong, 510970, China
}

\begin{abstract}
In order to solve the conflict between economic growth and environmental protection, the environmental impact assessment system used by western countries has been gradually introduced into China. It is a scientific and professional assessment system, which is regarded as the best tool to solve the conflict between economic growth and environmental protection. The implementation of the environmental impact assessment system can undoubtedly prevent some construction projects from having serious adverse impact on the environment. Through the comparison and selection of the feasibility schemes, the environmental impact of some construction projects can be minimized. Therefore, the environmental impact assessment system is regarded as an important pillar and effective legal system for the implementation of predictive environmental policy, which has attracted more and more attention in the world. In order to implement the strategy of sustainable development, prevent the adverse impact on the environment caused by the implementation of planning and construction projects, and promote the coordinated development of economy, society and environment, China has formulated the environmental impact assessment law. The law came into force on September 1, 2003 and was amended for the second time on December 29, 2018.
\end{abstract}

\section{Preface}

With the rapid growth of economy and the democratization of politics, people pay more and more attention to the environment. The living environment space that people need is not only based on economic production, but also environmental protection and cultural identity. In the past, China's development experience, with economic growth as its main goal, has created a worldfamous economic miracle. However, many waves of environmental protest have not disappeared with the progress of science and technology, and the recent protests are impressive. In order to solve this problem, China continues to maintain economic development and introduces the environmental impact assessment system of western developed countries as a weapon to solve the contradiction between economic growth and environmental protection. China is one of the first developing countries to implement the environmental impact assessment system of construction projects. In 1979, the eleventh session of the fifth NPC Standing Committee passed the environmental protection law of the people's Republic of China (for Trial Implementation), which established the environmental impact assessment of construction projects as a legal system for the first time. The environmental protection laws formulated in succession contain the principles and regulations of environmental impact assessment of construction projects.

\section{Connotation of environmental impact assessment system}

Environmental impact assessment (EIA) refers to the method and system of analyzing, predicting and evaluating the environmental impact that may be caused by the implementation of planning and construction projects, proposing countermeasures and measures to prevent or mitigate adverse environmental impact, and tracking and monitoring. Environmental impact assessment is the most important step in environmental risk management, the most important part of which is risk assessment, which is a comprehensive assessment of the various threats faced by the subject matter. The following will use risk assessment formula, risk assessment array and risk assessment process to clarify the connotation of risk assessment and quantify it as much as possible, so as to determine the priority and select the right measures should be taken. Generally speaking, it is to analyze the possible impact on the environment after the project is completed and put into operation, and put forward countermeasures and measures for pollution prevention and control. Importance and significance of environmental impact assessment:

(1) It provides scientific basis for decision-making of development and construction activities;

(2) To provide scientific basis for the rational distribution of economic construction;

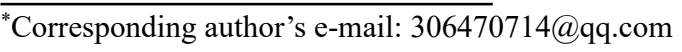


(3) In order to determine the direction and scale of economic development in a certain region, and to provide scientific basis for formulating regional economic development planning and corresponding environmental protection planning;

(4) It provides the basis for formulating environmental protection countermeasures and scientific environmental management;

(5) Promote the development of related environmental science and technology.

\subsection{Risk evaluation formula}

Risk $=$ Threat $\times$ Probability $\times$ Vulnerability $\times$ Criticality $(\mathrm{R}=\mathrm{T} \times \mathrm{P} \times \mathrm{V} \times \mathrm{C})$

In this formula, item " $\mathrm{T}$ " is whether the subject matter of the risk assessment will face the threat. Its value is 0 or 1. Item " $\mathrm{P}$ " is the objective possibility of the threat. Most of the data can be obtained through public data. Some data collection and analysis work should be done in advance. Item " $\mathrm{V}$ " is the vulnerability degree of the subject matter to the threat. Some vulnerability detection services can provide objective observation values. However, unless it is extremely high-tech, it is usually the most known one, so the rule of thumb is also very good. Item " $\mathrm{C}$ " refers to the impact on the overall operation of the subject matter if it suffers from the threat actually.

\subsection{Risk assessment array}

The risk assessment array is to help us easily judge the priority of risk management. Of course, the higher the risk, the more risk management is needed. This study believes that such a phased and sequential thinking process can help enterprise risk managers to do systematic evaluation and reference for future management priorities.

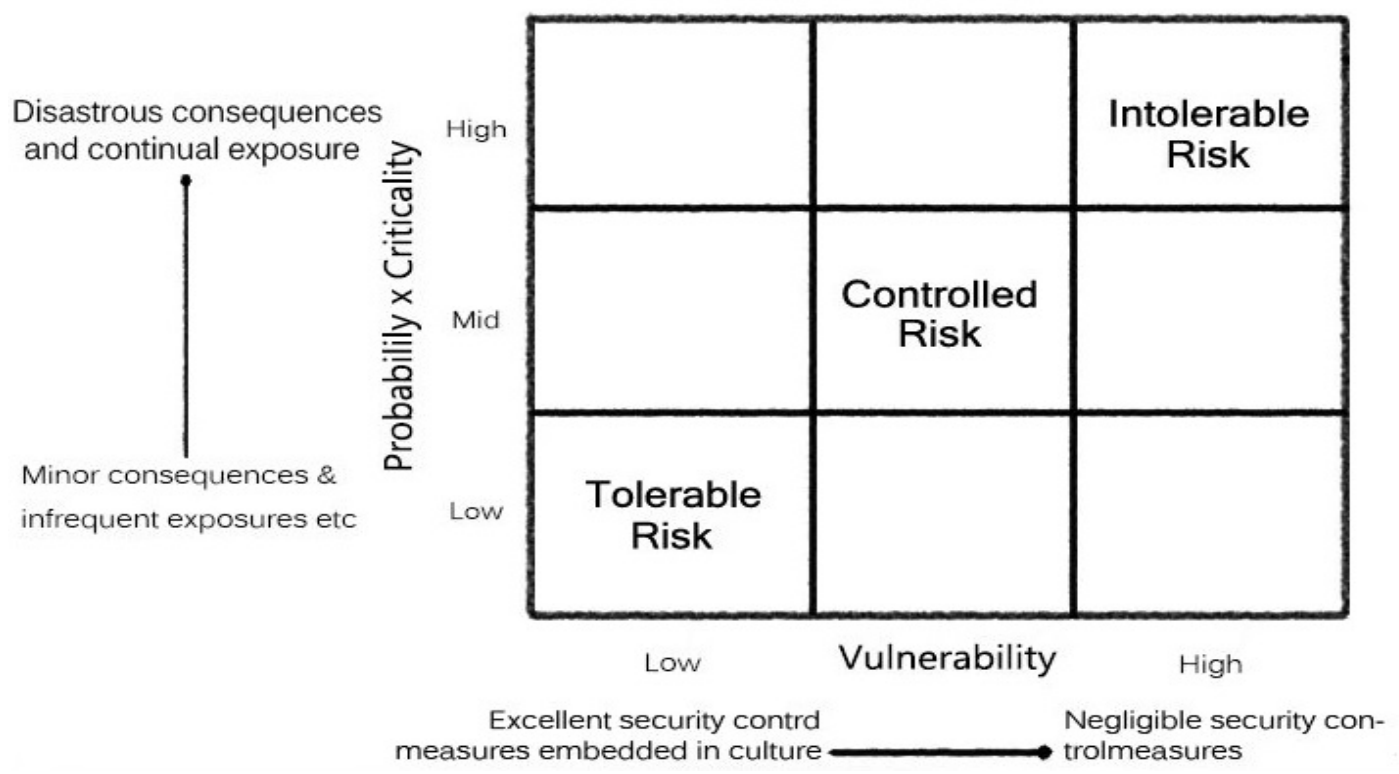

Figure 1. Risk assessment matrix

\subsection{Risk assessment process}

Risk assessment is an important process of risk management. The process of risk assessment defined by management internationalization standard is: risk assessment is the whole process of risk identification, risk analysis and risk assessment. In the iso31000 risk management standard, five basic problems need to be solved in the risk assessment process are clarified:

- What is the status quo? What can happen? Why did it happen?

- What are the consequences? What is the impact on the goal?

- How likely are these consequences to occur?

- Are there any factors that can reduce the risk consequences and the possibility of risk?

- Is the risk level tolerable or acceptable? Is there a need for further response?

In all kinds of complex system engineering, advanced risk assessment system is used to increase the safety and reliability of the project, especially in the field of life, environment or machine operation. Risk assessment has a long history in nuclear industry, aerospace, petroleum, railway, military and other industries. In addition, the application of risk control and risk assessment in medical, hospital and food industry is continuously promoted. Because of the difference of financial decision-making, environment, ecology or public health risk, there are different risk assessment methods among different industries.

\section{The legalization of environmental impact assessment system in China}

Environmental Impact Assessment Law of China has been passed and implemented for many years in 2003 . Major development cases must be reviewed by environmental impact assessment. The development of environmental impact assessment system mainly goes through the following three stages.

The first stage is the establishment stage. The concept of environmental impact assessment was first put forward 
in 1973, and the environmental protection law (Trial) issued in 1979 institutionalized and legalized the environmental impact assessment. The basic contents and procedures of environmental impact assessment are specified in the administrative measures for environmental protection of capital construction projects issued in 1981. After modification, the administrative measures for environmental protection of construction projects was promulgated in 1986 to further clarify the scope, content, management authority and responsibility of environmental impact assessment.

The second stage is the development stage. In 1989, the official environmental protection law was promulgated. Article 13 of the law states: "the construction of projects that pollute the environment must comply with the provisions of the state on environmental protection management of construction projects. The environmental impact statement of a construction project must evaluate the pollution caused by the construction project and its impact on the environment, stipulate the prevention and control measures, be pre examined by the competent department of the project and submitted to the competent department of Environmental Protection Administration for approval in accordance with the prescribed procedures. After the environmental impact report is approved, the planning department can approve the design assignment of the construction project. " In 1998, the State Council promulgated the regulations on the administration of environmental protection of construction projects, which further improved the legislative specifications of the environmental impact assessment system. At the same time, the scope of application, the opportunity of assessment, the procedure of examination and approval, and the legal liability of environmental impact assessment have been greatly modified. In March 1999, the State Environmental Protection Administration issued the management measures for the qualification certificate of environmental impact assessment of construction projects, which set China's environmental impact assessment on a professional road.

The third stage is the improvement stage. In view of the deficiencies of the regulations on the administration of environmental protection of construction projects and the needs of the development of the new situation, the environmental impact assessment law, which was implemented on September 1, 2003, can be said to be a new milestone in the development history of China's environmental impact assessment system and a sign of the improvement of China's environmental impact assessment.

The fourth stage is the perfection stage. On December 29, 2018, the Environmental Impact Assessment Law of the people's Republic of China was amended and shall come into force as of the date of promulgation. The following are the specific amendments to the Environmental Impact Assessment Law: (1) the competent administrative department of environmental protection is revised to the competent department of ecological environment; (2) the qualification examination and approval supervision of environmental assessment companies (technical units) is cancelled, and the construction units with ability can also prepare the environmental impact assessment report (form) on their own (3) The construction unit shall be responsible for the contents and conclusions of the EIA report (table), and the technical unit shall bear the corresponding responsibility in case of errors. For new credit supervision, the EIA approval department shall record the relevant illegal information of the establishment unit, the establishment host and the main establishment personnel into the social credit archives, and put it into the national credit information sharing platform and the national enterprise credit information publicity system for public announcement (4) The responsibility of false contents and incorrect conclusions in the EIA report (table) is the most important part of the revision of the EIA law (5) If the compilation unit has the above-mentioned illegal acts, the compilation host and main compilation personnel are prohibited to engage in the compilation of environmental impact report and environmental impact report form within five years; If a crime is constituted, criminal responsibility shall be investigated in accordance with the law, and the compilation of environmental impact report and environmental impact report form shall be prohibited for life.

\section{Conclusion}

Environmental impact assessment is a process, which focuses on the prevention function of environmental impact assessment before decision-making and development and construction activities. After the decision-making or the start of development and construction activities, through the implementation of the environmental monitoring plan and continuous research, the environmental impact assessment is still continuing, continuously verifying its assessment conclusions, and feeding back to the decision makers and developers, further modifying and improving its decision-making and development and construction activities. In order to embody the role of EIA, we must adhere to the sustainable development strategy and the concept of circular economy in the organization and implementation of EIA, strictly abide by the relevant laws, regulations and policies of the state, and achieve scientific, fair and practical. However, the controversy has not disappeared, and many environmental protest movements are still emerging. When the decision-maker's consideration is to develop the single oriented economy, the risk assessment is only a reference to standardize the decision-making behavior, and the underestimation of risk will become normally. Unfortunately, in the era of increasing globalization, risk and science are moving towards a more undemocratic way to construct its relative system, and the more unlikely the "prevention first" environmental protection policy will appear, which is an important topic that we must continue to pay attention to. The environmental impact assessment law was implemented in 2003. Its legislative purpose is to implement the sustainable development strategy, prevent the adverse impact on the environment caused by the implementation of planning and construction projects, and promote the 
coordinated development of economy, society and environment. During the 15 years of promulgation and implementation, this law has played an important role in preventing environmental pollution and ecological damage The purpose of amending EIA law is to achieve the goal of reducing environmental pollution from the source. Of course, in order to make EIA system play a better role, it is necessary to strengthen planning EIA, promote its participation in comprehensive decisionmaking and play a substantial role; Public participation should be strengthened, and social supervision should be used to prevent arbitrary intervention in EIA; Strengthen the rule of law to form the restriction and supervision of administrative power, and further promote the reform of administrative system.

\section{REFERENCES}

1. Barker, A., C. Wood. (1999): An evaluation of EIA system performance in eight EU countries, Environmental Impact Assessment Review, 19, pp.387-404.

2. Chambers, J.C. (2002): Community participation in brownfields redevelopment, In: T. S. Davis, ed., Brownfields: A Comprehensive Guide to Redeveloping Contaminated Property, 2 ed, Chicago: American Bar Association, pp.243-253.

3. Fischer, F. (1996): Risk assessment and environmental crisis: Toward an integration of

Science and participation. In: S. Campbell and S.S. Fainstein, eds., Reading in Planning Theory, Cambridge: Blackwell Publishers Inc, pp. 485-506.

4. Gismondi, M. (1997): Sociology and Environmental Impact Assessment, Canadian Journal of Sociology22(4), pp.457-479.

5. Plough, A., S. Kirmsky. (1987) :The emergence of risk communication studies: Social and political context, Science, Technology, \& Human Values, 12(3\&4), pp. 4-10.

6. Tzoumis, K., L. Finegold. (2000):Looking at the quality of draft environmental impact statements over time in the United States: Have ratings improved?, Environmental Impact Assessment Review,20,pp.557-578.

7. Winner, L. (1988): Do artifacts have politics? In: M. E. Kraft and N. J. Vig, eds., Technology and Politics, Durham: Duke University Press, pp.33-53.

8. Wynne, B.(2005):Risk as globalizing democratic discourse? Framing subjects and citizens. In: M. Leach, I. Scoones and B. Wynne, eds., Science and Citizens: Globalization \& the Challenge of Engagement, London: Zed Books, pp. 66-82. 